\title{
Mainstreaming Conservation Agendas in the Current Socio-Political Development Context
}

\section{Top B. Khatri ${ }^{1}$}

Key Words: Conservation, Green sector, GDP, Federalism, Restructuring, Educating and Awaring, Ecological and economic benefits, Liability, Select group of audience, Biopolitics, Positive guidance and conflict.

Conservation and development are inextricably linked. The earlier school of thought; "good ecology is good economics" vis a vis "good economy is good ecology" are equally relevant and mutually inclusive. Conservation initiatives in Nepal is often seen and viewed in terms of protecting wildlife and the subsequent conflicts emanating from it- for instance crop depredation and casualties by wildlife. It is often this negative side that takes the toll and overshadows the wider gamut of benefits accruing from conservation. It is an irony that even after three decades of conservation planning, this sector has not been able to position itself at the centre stage of developmental planning. In other words, green sector has not been able to market itself of its full potential; thereby receiving less than what it contributes at large. This has happened because we have not been able to educate and make aware our political leaders, planners and decision makers that play an important role in shaping the policy dimension.

People generally view conservation to be a vehicle for trouble creating rather than as a holistic approach to our very survival. Conservation today should become everybody's business. Time has come to make every effort to sensitize and make aware of the values it provides in terms of economic and ecological benefits that shapes the fundamental life support system. The contribution of green sector to the GDP, both in terms of ecological and economic value has to be accounted if the green sector is to position strongly to justify for allocating more resources in development planning. Only when people are aware and appreciative of the values and benefits, only then it will be accorded a priority. The current scenario of viewing the green sector as a liability rather than an asset is primarily due to the inability to present the case strongly at the highest planning level. Furthermore, it is urgent to educate and enlighten the policy and decision makers to understand the value and importance of conservation.

\section{Why this select group}

The most important category of people that need to be educated and sensitized on this front are (a) the political parties (b) lawmakers (c) the parliamentary committee that looks after the natural resources and the (d) decision makers at the highest level.

\footnotetext{
National Project Manager,Conservation and Sustainable Use of Wetlands in Nepal (CSUWN), Babarmahal, Kathmandu,tbkhatri@wlink.com.np.
} 


\section{How to go about?}

In order to mechanize this, there should be a coherent strategy to communicate the value of biodiversity conservation to the targeted audience. For this, the conservation community in collaboration with a think tank comprising of biodiversity experts, economists, retired bureaucrats, planners, PA managers, thinkers, mentors and opinion builders can sit together to design a ready to impart an awareness and sensitization module targeting the above audience. The thematic subcommittee of the National Biodiversity Coordination Committee (NBCC) can also become an important platform to help design and implement this strategy. The content and scope of the module may vary depending on the audience and this should become a continuous process and not a onetime affair.

Efforts must be made to ensure that this select group of people can effect changes to the perception, value and understanding of conservation so that this sector could receive and draw adequate attention from all sides.

Concerted efforts must be made to ensure that the conservation agenda is mainstreamed into the general manifesto of political parties so that this sector also receives full political commitment. Political commitment is perhaps the most valued commodity for biodiversity conservation in light of the political instability and the process the country is poised to embark upon.

\section{Why is this urgent?}

This initiative is urgent primarily for two reasons;

\section{Avoiding Bio-politics:}

It is the natural resources sector that has suffered the most during the course of political turmoil, conflict, and transition. It is this sector that bears the brunt of all shocks. This sector has also become an ideal playground for politicians to entrench their vote banks. Over the years, the country has lost a significant share of its forest resources and many more will be lost in due course of time as we have established a bad practice of providing forested land for resettlement and other associated activities. We cannot afford to lose further our precious forest assets that are so valuable for our well being. Further, it is urgent to educate and aware policy and decision makers on the values of conservation. Along side with the political transition and the proposed restructuring of the state, it might even be important to educate the law makers on the environmental and economic benefits that forest resources provide with the new opportunity from the window of carbon trading. This natural asset will loom at large in the political and economic domain in the days ahead.

\section{Positive guidance}

It has become urgent for the reason that the political actors who are supposed to debate and discuss and chart the future course of actions in the areas of natural resource governance in light of the proposed restructuring of the state to understand the values of conservation. Once they are educated and made aware, there is very little chance to get misguided and fall into the trap of the activists that generally portray the negative aspect of conservation. It has been noticed many a times, our policy makers have fallen into the trap of activists due to their ignorance. 
This sensitization and awareness building initiative will provide a unique opportunity for our law makers to gain insights of the values of conservation and bring those experiences in shaping the new constitution making process by integrating the environment and conservation agenda as one of the priority area. Therefore, it is the duty of the professionals and bureaucrats to educate and enlighten them.

\section{Ways ahead: building on success}

Our country has undergone unprecedented changes in terms of political transformation. People have a lot of aspirations with the changed context. In order to meet those aspirations, we must reorient our institutional capacity to cater to those needs. People aspire for changes, but changes do not happen overnight. Development changes can happen and become sustainable only when they are backed by strong value additions. Value additions are made only when they evolve over time through best practices and lessons. Progression through evolution is the way forward to development. Development will fail if it is not backed by positive actions. Very often, things do not move as we fail to make fair judgment. The success that Nepal has made in conservation arena is a by-product of good commitment, stewardship, and trust on both part of the government and local people. Therefore, if we envision of making some changes, it must value add on the lessons learnt. Changes for the sake of changes will yield nothing; it must be able to bring new innovations. If we fail to bring changes, we will become victims of our own success.

\section{Conclusion}

Therefore, in order to materialize and make things happen, it is urgent to work strategically to educate and aware our select group of actors so that they understand and appreciate the values of natural resources and become proactive to safeguard the natural assets for the benefit of present and future generations before it is too late.

Wetland Friends of Nepal (WFN) is a non profit organization (NPO) founded in 2005 and represents a non-governmental wetland working network of Nepal. It is formed as a result of group of young professionals and amateurs wanting to come together to respond the urgent need of the worsening situation of wetlands and associated biodiversity in Nepal. It is committed to conserve and manage wetlands with local people's participation for their benefit, while maintaining environmental integrity according to the terms and spirit of the Ramsar Treaty.

\section{Weflano and Wetland Friends of Nepal}

Hariyokharka,IOF Pokhara 